\section{(19) Lumeriations}

\section{or}

\section{$X$ RAYS IN THE DIAGNOSIS OF EARLY CARCINOMA OF THE STOMACH."}

\section{BY}

Professon MARTiN Hatdek, M.D.,

\author{
WILHELMINENSPITAL, VIENNA.
}

The vital statistics of most countries show a steady decline in the birth rate and a contemporary increase in the average duration of life-in Germany an increase from the age of 38 to 57 years in the last decades. The decrease in the death rate is attributable to the progress of medicine, and especially to the methods adopted in grappling with the problems of infantile mortality, tuberculosis, and infectious diseases. One other fact stands out clearly from the statistics (in which in latter times diseases due to old age and debility greatly preponderate as causes of death) ramely, that next to cardio-rascular diserse comes carcer. The war on cancer is therefore becoming a problem of ever-increasing importance to the medical profession.

Of all falal cases of cancer, cancer of the stomach is shoun to be the commonest. Its victims constitute a percentage of the total cancer deaths which varies in different countries from 35 to 40 . Deaths from cancer of the intestine, uterus, oesophagins, and breast are far less common. So that if we aro to wage effective war on cancer, then early recognition and treatment of cancer of the stomach are clearly indicated as the most promising line of attack. This is the reasoning which has apparently been followed by the Section of Radiology and Radiotherapeutics of the British Medical Association in selecting the early diagnosis of cancer of the stomach, and the relation of $x$-ray examination to that problem, as the subject for discussion at its first session.

\section{Success Atrained up to the Present Time in} Radiological Diagnosis of Gastric Cancfr.

We can best envisage the prospects of success in the future by drawing upon the accumulated experience of the past; $x$ rays have now been employed in the cinical diagnosis of gastric carcinoma for twenty years. During that time $x$-ray examination has in all countries become so general a practice in diseases attended by gastric symptoms that its omission amounts to a professional error. In many thousands of cases gastric carcinoma has been correctly diagnosed by its aid, and a very large number of patients have been submitted to radical operation. The number of late laparotomies-that is, operations at which incurable cancer was found-has decreased, as has also the number of unnecessary laparotomies, made as a result of a wrong diagnosis of cancer. Exploratory laparotomies, undertaken to clear up the doubt as to the presence of cancer, have become very rare, but were still of daily occurrence twenty years ago.

And again, on the question whether a gastric carcinoma is operable or not the $x$ rays can give important information. This fulfils the expectation which $I$ entertained as to the role of $x$ rays in my paper, "Die Bedeutung der Magenradiologie für die Chirurgie," published in conjunction with Clairmont in 1911. ${ }^{1}$

As numerical evidence of the reduction of late laparotomies I quote the publication by Schönbauer and Freided ${ }^{2}$ of the Eiselsberg Clinic in Vienna "Ueber einige besonders lange Dauerheilungen nach Magenresektion wegen auch histologisch nachgewiesenen Carcinoma rentriculi." of the 661 cases of gastric carcinoma in the period 1901-14, resection was done in 26.2 per cent.; of the 535 cases in the second period resection was done in 37.9 per cent. The primary mortality (18.5 per cent.) was the same in both periorls. A comparison between the vears 1908 and 1024 shows an increase of resections of 18 per cent. (from 22 per cent. to 40 per cent.). The increase in radical operations can be put to the credit of $r$-ray diagnosis, without, however, losing sight-of the improvements in surgical technique. Yet 40 per cent. of possible radical operations still means more than 60 per cent. of operations undertaken too late-a figure which corresponds to the average of surgical statistics.

In the surgical department of the Wilhelminenspital in Vienna, for which $I$ have done the $x$-ray examinations during the past nine years, the statistics show the same proportions. In all places must be added to these a great number of patients; in whom inoperability of the disease is recognized beforehand, so that not even an exploratory laparotomy is attempted. Thus the death rate in gastric cancer is still extraordinarily high.

How, then, can we attain to further progress? Are: we merely to subscribe to the views of Boas (Berlin), the famous expert on gastric disease, who doubts the possibility of an early diagnosis of gastric cancer, on account of the more or less extended latent period connected with the disease? Those who have devoted much time to $x$-ray examination of the stomach, and have become convinced that $x$-ray methods allow gastric cancer to be recognized considerably earlier than by any other met!od of examination, will not incline towards pessimism, but will believe in the possibility of yet further progress.

\section{Causes of Delayfe Rapiological Diagnosis of Gastric Carcinoma.}

We can distinguish four causes of delayed radiological diagnosis: (1) the latent period; (2) delayed $x$-ray exismination; (3) faulty $x$-ray examination; and (4) a defect which still exists-namoly, the incompleteness of our present-day technique.

The latent period-that is, the time during which gastric carcinoma remains srmptom-free-is still the prime factor to be reckoned with. This period is of varying duration, depending on the type and site of the tumour. In carcinoma of the body of the stomach, especially with diffusely infiltrating growths, local symptoms often occur so late that, howerer prompt the examination, there is but rarely a chance of finding radical operation possible. The symptoms which lead to the earliest recognition of the growth are pyloric stenosis and haemorrhage.

Delnyed $x$-ray examination has its cause, apart from latency, first in the often insidions origin of the disease and its indefinite symptoms; secondly, in non-recognition of the gravity of the local symptoms by the patient and his doctor alike. In the history of the cancer patient we usually hear of symptoms which have already existed, treated or untreated, for a considerable number of months, but at the same time we find such an advanced stage of carcinoma that we would have been quite able to diagnose the condition many months earlier. One way to improve the early diagnosis of cancer of the stomach would lie in eliminating this loss of many months' time and carrying out $x$-ray examination without delay.

Faulty $x$-ray examination is for us the most important subject. ' In my work, principally as consulting specialist, I have had many opportunities of convincing myself that the possibilities which an $x$-ray examination offers of deciding whether gastric caicer is present or no are not sufficiently utilized. I strongly maintain that by a sufficiently precise examination, supported by sufficient experience, we are in a position to establish at an carly stage with a considerable degree of certainty whether a carcinoma is present or whether this can be definitely excluded. Since, however, the results of $x$-ray examination are often unsatisfactory, and since, in consequence, $x$-rav examination of the stomach does not enjoy the universal confidence which should be reposed in it, I must refer to the sources of errors.

At one time the difficulty of examination of the stomach was underestimated. Especially in connexion with $x$-ray examinations, the lay public, and unfortunately a good many doctors as weli, think that the $x$-ray apparatus is the important thing for establishing a correct diagnosis. A man sometimes undertakes the work, without sujervision, after a short period of mainly technical training, without possessing the ruiliments of knowledge necessary for the responsible task of the radiologist... We must make everybody realize that the result of an $x$-ray examination 
depends far more on the skill of the investigator than on the quality of the apparatus.

The examiner, when he is an $x$-ray specialist, must arm himself with a thorough basic knowledge of pathological anatomy and internal medicine; similarly, a physician or surgeon who uses $x$-ray examination of the stomach independently in his cases must bo familiar with general radiology. In cases where he does not feel certain of his own findings he must never hesitate to consult a radiologist with special experience. I find that $x$-ray consultation is far too seldom asked for, and this is a serious misfortune for the patient.

To attempt $x$-ray diagnosis of conditions of the stomach and duodenum without being able to employ photography as well implies a defective method. Although screen examination gives so much information, yet it must be supplemented by photography, and, moreover, by films taken with special skill and first-rate technique in order to obtain a permanent record of the significant signs. The liagnosis of early carcinoma, bound $u p$ as it is with the study of the "relief-pattern" of the mucous membrane, is, apart from radiograms, unthinkable. But even an experienced radiologist will surely make mistakes if too many examinations are required of him and if he undertakes them.

Personally I allow about half an hour for each examination I make, and will not undertake to carry out more than six to eight consecutive examinations. At the same time, I do not always complete a stomach investigation in one day, but sometimes explain that a second examination is necessary on the next day under different conditions. How, then, can those who carry out twenty or even thirty stomach examinations in a few hours expect to obtain equally good results? Such conditions do exist in many hospitals, and still more in the " pancl" clinics, which are increasing in number. Superficiality and the danger of fatigue are inimical to accurate work. Many important aids to diagnosis are perforce omitted for want of time, or often in the interests of economy, which such conditions demand. Even if the results are only 10 per cent. worse than when the radiologist devotes himself entirely to his task of attaining a conclusive diagncsis, what patient would like to find himself among the 10 per cent. in which a stomach carcinoma is not recognized in time, simply because of insufficient examination?

Overburdening of the radiologist must therefore be stigmatized as a further source of error in the diagnosis of stomach carcinoma.

\section{Technique and Method of Investigation of the} Sтомасн.

There is no standard method or technique amongst raliologists engaged in stomach examinations. Neither screning nor radiography is carricd out to the same extent or on exactly similar lines by different workers. But the whole outcome depends on bringing to light and critically analysing the appearances in detail.

I should like to describe my own method of investigation -a method progressively developed over twenty years. In every case I personally take an accurate history of the illness, because it forms a frame into which the $x$-ray findings are fitted; it is, however, often treated in a biased manner by the referring physician.

Screening of the chest is carried out before each abdominal examination. Often this reveals the cause of the symptoms hitherto ascribed to a carcinoma of the stomach; such as a serious aortic disease, or a tuberculous process in the lungs which may be accompanied by tuberculosis of the small intestine. We shall not be likely to overlook such lesions as metastatic carcinoma in the lungs, secondary malignant pleurisy, or a clinically undiagnosed bronchial carcinoma.

For screening of the stomach the patient stands on a low footstool, and I begin by palpation to estimate the tension of both recti, the possible presence of localized tenderness, or abnormal resistance. In weak and anaemic patients, and especially in those who are cachectic, I omit the palpation, otherwise the investigation in the erect position may be interrupted by the development of cerebral anaemia. The examination of the stomach usually begins with the motility test, four hours after the patient has taken a small portion of thick gruel with 70 grams of barium sulphatc-so far just like the old Rieder meal. For the diagnosis of carcinoma this test for residue, apart from any secondary pyloric stenosis, 1 . $y$ be of importance, inasmuch as a residue, or " surface film," on an ulcerated carcinoma may be the only visible remainder of the contrast meal.

Now follows the second filling of the stomach: this time not with gruel, but with a thick barium mixture just fluid enough to drink (double meal method). The total of this amounts to $300 \mathrm{c.cm}$., in which the quantity of barium is about 120 grams. Raspberry juice is employed to improve the taste. With the barium which I use (supplied by Merck) a special suspending agent is not necessary. The large quantity of barium used considerably diminishes the tendency of the contrast substance to sediment. Careful churning up with a whisk is sufficient to produce a suspension of the barium which will remain for a long time without sedimenting.

First of all the patient drinks only one large mouthful of about 20 to $30 \mathrm{c.cm}$. This is followed during its passage down the oesophagus. If the swallowing of fluid appears to me to be delayed in the least, or if the patient complains of difficulty in swallowing, I never omit giving him a small gelatin capsule filled with 1 gram of barium to swallow. If this, when followed by a drink of water, passes down the oesophagus and without hindrance through the cardia into the stomach, then a malignant stenosis can be excluded. Conversely, the holding up of the capsule, despite repeated drinks of water, is of great service in the early diagnosis of carcinoma at the cardia, whether originating in the cardia itself or in the upper part of the stomach. As an example $I$ will quote the following case.

CaSE I.

Recently I examined a female patient of 60 , whose symptoms appeared to the physician referring the case to be suspicious of stomach carcinoma. I found nothing unusual in the stomach except a slight diminution in size of the gastric air bubble on its medial aspect. Fluid barium flowed without obstruction into the stoniach, and the gastric peristalsis and contour were quite normal. A small capsule, however, remained stationary close to the cardia. The film (Fig. 1) showed that the deformity of the

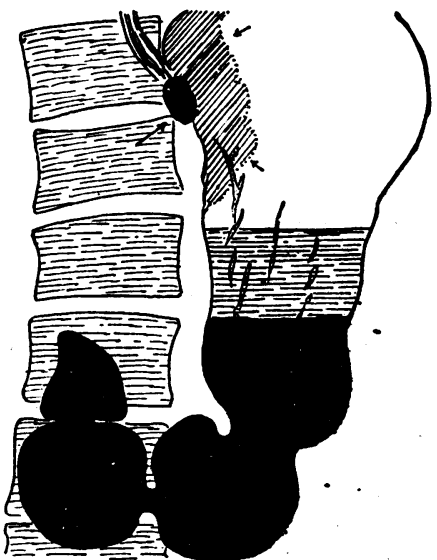

FIG. 1.-Nedullary tumour in fornix. A small opaque capsule held up at the cardia. Stomacil shadow elsewhere normal.

gas bubble was due to the shadow of soft-part density caused by a medullary tumour, which projected into the Jumen of the stomach from the lesser curvature. The patient had no definite dysphagia, but only complained of the stomach. With screen examination alone, without the use of the capsule, I might have failed to observe it.

If the small portion of about $30 \mathrm{c.cm}$. of suspension passes into the stomach, it is dispersed by compression with Holzknecht's "distinctor" or a pad. The thin film of barium between the folds of the gastric mucosa throws them into clear relief.--The "Magenblase" and the wall contours of the fornix, the course of the mucosal folds in the body of the stomacl and in the pyloric segment are 
exanined successively with a small diaphragm and compression. Retained secretion interferes with the study of the mucosal " roliof pattern." Secretion is recognized by a horizontal fluid level which is visible in the fasting condition helow the Magenhlase, by the paleness of the marking of the folds, by the very pale grey shadow which the contrast substance produces, and by an early crescentic sediment of the barium in the lower pole. If the marking of the folds is distinct, minute niches between the folds, or an abnormal thickness or irregular course of the folds, may be noticed. Irregular central shadow defects, or barium rests in the crater of a tumour or in the furrows between the lobules of a medullary carcinoma, lead to a definite diagnosis of tumour. With polypi or non-malignant tumours the borders are circular and well defined. After another drink the pars pylorica, the pylorus, and the bulbus duodeni become visible.

Now the patient drinks the remaining suspension, during which time the increasing filling of the stomach is watched, screening it at different angles. Observation is then directed to the flexibility of the walls, the sharpness and the regularity of the contours, and the course of peristalsis. With atonic stomachs the highest parts remain empty in the standing position. In these cases the contents of the upper third are dammed back while the patient: drinks, by closing the lumen by pressure of the hand, or of the "distinctor" below the left costal margin. This procedure completely separates the folds in this part, which are now examined in different directions. In this way the very inaccessible tumours of this portion, so easy to overlook altogether, can be brought to light.

The usual examination in the standing position is often insufficient for the lesser curvature of the par's pylorica, the most important part of the stomach in the diagnosis of carcinoma. With atony, hypersecretion, and dilatation of the stomach, the contrast shadow is crescentic, and in spite of massaging the contents upwards, the lesser curvature is not reached by the barium and the bulb is poorly filled. In this case the patient is laid for a few minutes on a couch, on his right side, with the pelvis raised. After this preparation he is examined again standing up, and now the filling of the pyloric canal and of the duodenal cap is often satisfactory, or easily effected by pressing out the contents of the stomach. If manual mancuvres are impossible owing to the patient's condition-for instance, in anaemia, or with an inflamed irritated condition of the peritoneum, which may be recognized by increased tension of the rectus on one side-an examination with the patient lying down is most effective.

1 attach great importance to the examination made in the prone position. In this position the contents of the stomach return from the backwardly directed fornix (formerly called "fundus", by the anatomists) into the ventral part-that is, the pars pylorica, which now becomes expanded to its maximum. The flexibility of the walls, the jerfect curve of the pyloric terminal contour, and the normal convexity of the outlines are now most clearly visualized. The prone position is indispensable for the examination of the peristalsis on the lesser curvature. It must not be forgotten that quite a number of carcinomata are confined to the lesser curvature and leave the greater curvature completely free. In, these circumstances perfect peristalsis is seen on the greater curvature in the standing position, and there is a risk of an early or even quite extensive disease of the lesser curvature being overlooked if it takes the form of a flat infiltrating growth.

The observation of the mucous membrane with partial filling, together with the flexibility of the walls and the regular course of peristalsis in the prone position, is the safest protection against overlooking a carcinoma. The diagnosis : of small tumours depends on a scrupulous observation of this rule.

'The object of Fränkel's (Berlin) rinematography is to diagnose rigidity of the wa!ls in a small or large section of the lesser curvature by local absence of peristalsis. This is done by means of numerous photographs, taken in quick succession and projected on to a diaphragm. The photographs for this purpose are made in the standing position. The method of examination which I employ, and which $I$ have just described, does, I think, render this expensive apparatus superfluous. As a matter of fact $I$ decidedly prefer an examination of the peristalsis of the lesser curvature in the prone position to one made in the standing position; for the waves of both curvatures are of equal depth in the prone position because the pressure of the gastric contents then affects both curvatures in an equal degree.

I use the examination in the supine position in order to see the mucous folds in the pars pylorica, for in this position most of the contents of the stomach flow to the fornix, and the pars pylorica is then only scantily filled. Bat the examination in this position is of small importance compared with that in the standing and prone positions, and is employed only in rare cases.

A single $x$-ray examination gives the desired results in the great majority of cases, but not always. If the motility examination has shown gastric retention of food or secretion, then the detailed examination becomes more difficult, and its results camnot be relied upon as regards fine anatomical points. The patient has to. come for a second examination, which may quite well take place on the following day. The patient takes only liquid in the evening and comes the next dar for examination in a fasting condition. Before the examination he is made to lie on his right side for at least two hours, his pelvis being raised by a pillow. In this position the pylorus becomes the lowest point of the stomach, and the stagnant conterits can he most readily removed. This method of evacuation, of the stomach has served me better than evacuation by tube, which is usually incomplete. Into the completely emptied stomach is now introduced about 5i) c.cm. of very thick barium cream, and the examination of the mucous membrane with compression is made in the standing and lying positions. Then the examination already described is continued with the full drink. If the preparatory measures just described have failed to remove the retained secretion, then there is cither a pyloric stenosis, the cause of which, ulcer or carcinoma, can be ascertained, or there is hypersecretion of higher grade, due to ulcer. The diagnosis is made from the combination of the anatomical abnormality with disorder of function.

Photography is used at every important stage of the screening in order to fix the characteristic appearances. It is upon the care and judgement applied to the preparation of the part for the radiogram-whether by suitable filling of the suspicious segment of the stomach, by compression, or by the use of the correct diaphragm and the angle of radiation-that the whole prospect depends of obtaining pictures of decisive diagnostic ralue.

To distribute the contrast-substance to best advantage in stomach and duodenum I use Holzknecht's " distinctor" during screening, and when necessary, for quite short periods, one or even both hands. Though I have not used lead-rubber gloves, and have made innumerahle examinations, my hands have in twenty vears suffered no ill effects. The patient's body, with a tissue thickness of some 20 centimetres, constitutes in the usual antero-posterior examination an excellent protective medium. But, of course, exposure of the hands in the rays must be rigidly limited to the most important manouvres of palpation or distribution of the contrasting substance. In making radiograms I use translucent pads (wadding sewn up in material) of rarious sizes to compress and spread out the barium.

The work of Berg4 $^{4}$ and Chaoul $^{5}$ has done much to popularize a similar technique. Berg prefers a very small diaphragm. Chaoul makes films giving a more extended view. He examines in the prone position on his special support, with a mirror below for observation, and makes compression with rubber air bags blown up to different degrees of tension. He uses a barium tragacanth mixture. I am engaged in trying out the suggested modificaticns of technique, but have not yet reached a definite decision whether, or to what extent, my own results can be thereby improved.

\section{My own Results in Cancer Diagnosis.}

Coming now to the results of my own examinations, I should like to test the reliability of my technique on three counts: Has it sufficed to determine sligint changes 
in the gastric wall? Have I overlooked an existing carcinoma? Or, on the other hand, has a commencing carcinoma been wrongly assumed to be present?

The number of really small carcinomata discovered by me in the earliest stage is very small. Much larger is tho number of quito operable carcinomata which I have sent to operation. Most numerous of all my cancer cases have been those in which I was compelled to report inoperability.

Figs. 2 and 3 show a quito resectable tumour above the angulus. In the first, with a small meal, the mucous folds are shown, and terminate at tho edge of a dishshaped carcinoma. The second radiogram, after complete filling, shows what might be readily confused with an ulcer niche, because this also shows projection of the

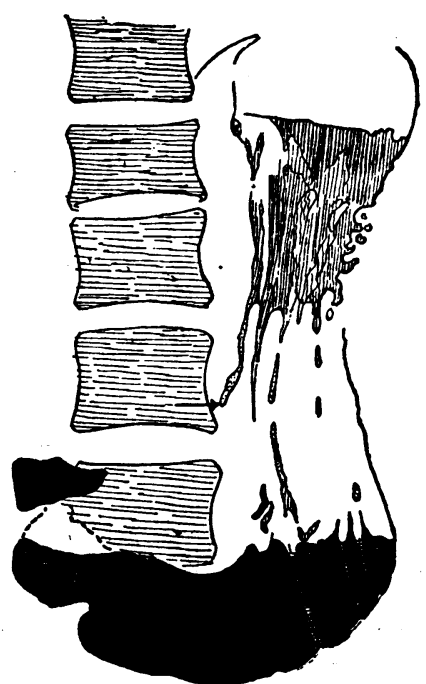

FIG. 2.-Adenocarcinoma at angulus.
Mucosal "relief pattern" shows sudilen interruption of rugae (arrow). surrounding stomach

wall into the lumen, due to swollen mucosa. But the folds couverge towards an ulcer niche; they merely terminate abruptly before they reach a carcinomatous crater-a differential diagnostic point of great significance.

CASE II.

Fig. 4 shows a dish-shaped adenocarcinoma on the prepyloric lesser curvature (histologically, ulcerating carcinoma). The lesser curvature (histological, a female aged 44 , had

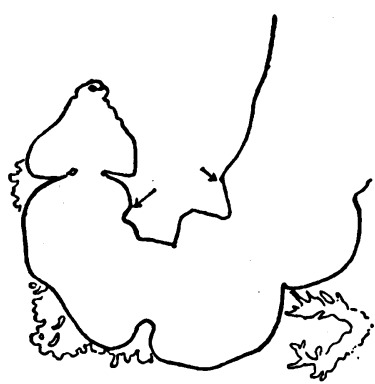

Fia. 4.-Prepyloric carcinoma on lesser curvature with crate and marginal ledges. suffered from griping pain and tenderness over the epigastrium for four months. Another observer had interpreted the appearance as ulcer niche. My own diagnosis was crateriform carcinoma. The decisive point, to my mind, was the recognition of angular projecting ledges on the film proximal to the pylorus and at the angulus (arrowed). These ledges are really typical of a carcinomatous filling defect, whereas ulcer shows smoothly concave semicircular contours on the edges of the mucosal swelling which surrounds the niche.

On the other hand, a shadow projecting into a filling defect signifies carcinoma. Fig. 5 relates to a still smaller carcinoma.

CASE III.

The patient was a woman of 40, of healthy appearance, well nourished, with slight symptoms of over six months? duration. An

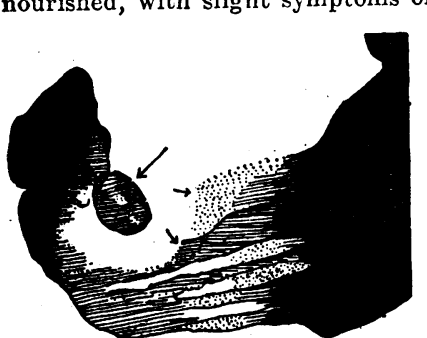

Fig. 5.-Small prepyloric carcinoma, with surrounding wall of infiltration. The rugae are interrupted at the edge of the zone surrounding the central barium deposit.

filling defect shows an indistinct outline against the surrounding barium. In the supine position the mucous folds proximal to the defect are clearly seen to terminate abruptly (Fig, 5). No resistance. No tender pressure point. The duodenum fills normally. The bulb has regular contours; its medial recess is partly covered by the prepyloric barium mass. My interpretation is : Not ulcer, but a small carcinoma just proximal to the pylorus, with a deep crater. The decisive point in the diagnosis is the abrupt termination of the longitudinal folds about a fingerbreadth from a central sharply defined barium deposit, and the clear rim surrounding the deposit as a constant filling defect. The deposit was not inter-

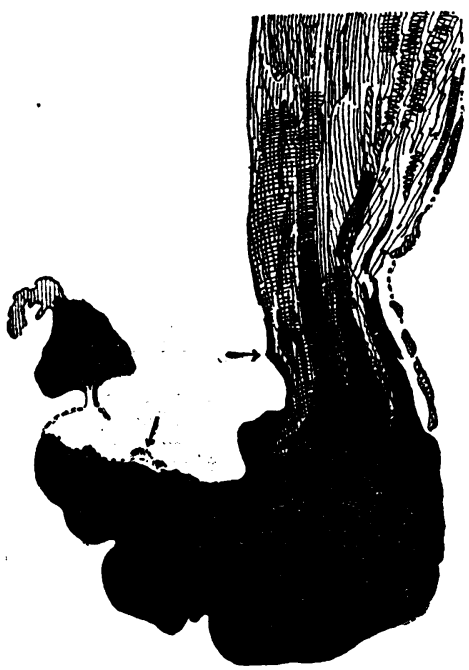

FIG. 3.-The same case with stomach ma crater with infiltration and marginal ledgcs. preted as an ulcer niche, in spite of its well-defincd outline.

Macroscopic examination of the resected specimen is also in favour of ulcer, showing a flat dish-shaped crater, the size of half a hazel-nut, within an induration of small extent.

Histological Report: Strongly infiltrating carcinoma with deep ulceration.

Two years after the operation the patient is free from symptoms and in perfect health.

It is worth observing that the radiological interpretation of the changes as being due to carcinoma were even more accurate than the macroscopic examination of the resected specimen, at which it was assumed tö be ulcer.

A small easily operable scirrhus is shown in Fig. 6. Circumscribed scirrhus almost always originates $0 ! 1$ the lesser curvature just proximal to the pylorus. Its pathognomonic feature is a "spigot" formation. The spigot lies on the lesser curvature, since the flat tumour of a fibrous nature with relatively few cells narrows the lumen by drawing the greater curvature towards the lesser. The stomach wall is therefore free from tumour at the point where it suddenly turns towards the lumen.

In prepyloric ulcer and benign thickenings of the gastric wall the lesser curvature is flattened, the convexity of the greater curvature maintained. The narrowed strip of shadow is therefore eccentrically placed in the opposite sense to what occurs in scirrhus (Fig. 7).

Medullary carcinoma offers the

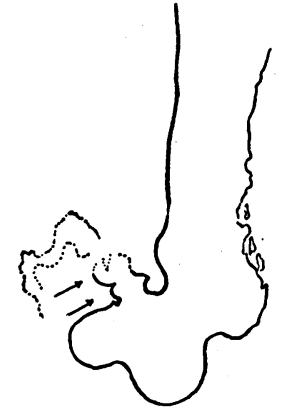

Frg. 6.-Small prepyloric scirrhus on lesser curvature. The characteristic point is the indrawing of a broal segment of intact greater (arrows). best chances for correct radiological diagnosis, for palpa. tion, and for operation. Even when situated high up it is still quite resectable, because the stomach, having no tendency to shrink, retains its normal shape and mobility. Small medullary carcinomata show a central filling defect, like benign tumours-adenoma, fibroma, etc.-except that in these cases pedunculation and a well-defined edge of the filling defect may reveal their b e $n$ i g $\mathbf{n}$ nature.

Fig. 8 refer's to a $t \mathrm{u} \mathrm{mo} u r$ which was recogn i zed as benign a $\mathrm{nd}$ c o nsisted of

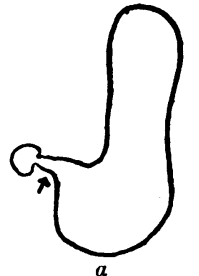

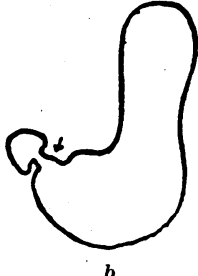

$b$

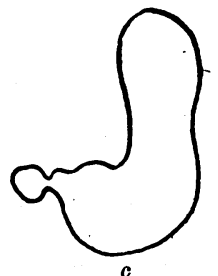

c
FIG. 7.-(a) Typical of prepyloric scirrhus. The barinm shadow lies along the lesser curvature. (b) Typical of benign narrowing. The barium shadow lies along the greater curvature. (c) Upward convexity of lesser curvaseveral fibro-

adenomata up to cherry size (operative confirmation). It is never possible to diagnose the benign nature of a tumour with complete assurance-first, because the differential diagnosis is not quite certain; secondly, because malignant degeneration not uncommonly occurs in a benign tumour. 
Wechselmann ${ }^{6}$ estimates that carcinomatous degeneration occurs in possibly 60 per cent. of all adenomata. Konjetzny? actually states that the majority of gastric carcinomata originate from adenomata and polypi, or at all events from an arlenomatous precancerous stage.

The expert radiologist should therefore never assume the responsibility of having delayed a suggested operation, but should be prepared to accept the reproach of having supported rather than opposed an operation in a doubtful case. In my department a case of prepyloric polypi was watched for three years, and gradually began to show signs of malignant degeneration-namely, progressive growth and increasing loss of clefinition of the contours. Operation was continually refused by the patient, who had only slight symptoms. At the necropsy a carcinomatous degeneration of the tumour was found, which still retained a recognizable polypoid character.

According to the foregoing conception the carly diagnosis of adenocarcinoma and medullary carcinoma is to some extent hound up with the early diagnosis of adenoma, fibroma, and polypi. How small a polypus can be detected

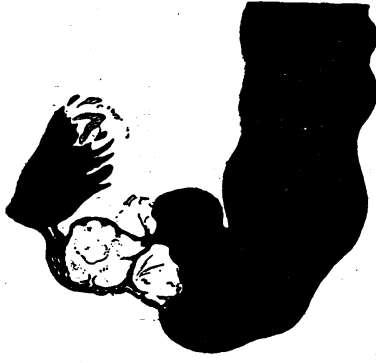

Fig. 8.-Prepyloric fibro-adenoma resembling a commencing medullary carcinoma. patients in whom a decision as to the cause of the symptoms can only be made by re-examination.

With this system of checking results not a single case has come to my knowlelge in the post-war period in which, after 1 have excluded carcinoma in a clinically suspicious case, gastric carcinoma has eventually been shown to exist, either by operation or by the further course of the clisease.

The only exploratory laparotomy made in recent rears, in spite of a denial by me that cancer was present, was performed in the following case.

CASE V.

In a man of 73 , with vomiting, wasting, and cachectic appearance, another observer had made an $x$-ray diagnosis of carcinoma

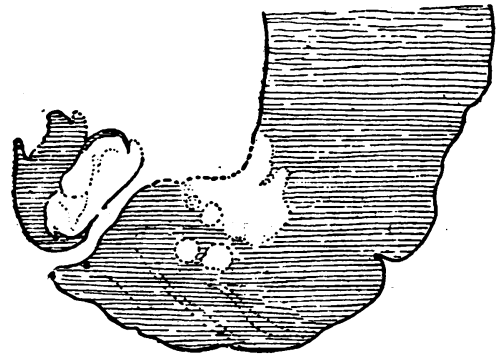

FIG. 9.-Large polypus in duodenal bulb. Small polypi in pars pylorica. (The translucent area at angulus was caused by compression.) of the body of the stomach. I found no carcinoma, only an organic cascade stomach with adhesions of the anterior stomach wall to the belly wall. As he was feeling very ill the patient himself wished to have the operation which had previously been recommended to him

I attended the laparotomy. On opening the abdomen the surgeon found extensive adhesions, especially in the gall-bladder region. The gall-bladder was small, shrunken, and full of stones. The stomach by $x$-ray examination is seen by reference to Fig. 9 . A date-sized polypus was situated close to the pylorus and was invaginated into the duodenum, as the operation proved. The radiogram clearly showed three translucent areas from linseed to pea size, arranged in clover-leaf fashion, which corresponded to polypi of exactly this size.

The early diagnosis of tumours of the upper part of the stomach, inaccessible to operation on account of their position, is, unfortunately, merely of diagnostic and prognostic importance, and does not affect their treatment. The same is true at the present time of cancers of the oesophagus and cardia.

\section{CASE IV.}

A commencing carcinoma of the ulcerating adenocarcinoma type is shown in Fig. 10. The changes could only be clearly recognized in the partly filled stomach, and the differential diagnosis from ulcer was by no means certain. With complete filling (Fig. 11) the stomach appears normal. The contrast between these two pictures proves how utterly inadmissible it is to make the first examination after the patient has drunk thc cutire meal. There was no operation, and the patient died fourteen months after the first examination:

If we are right in our opinion that gastric carcinoma is recognizable in an early stage, then negative $x$-ray findings, denying the presence of a suspected carcinoma, must also be considered reliable. It has for

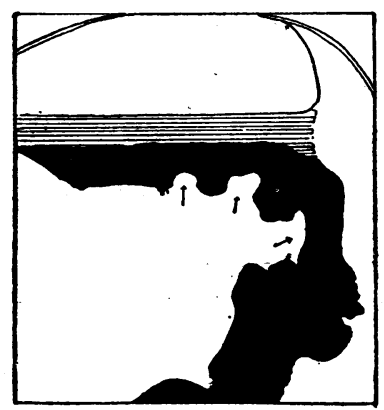

FIG. 10.-Commencing adenocarcinoma high up in body of stomach. In the partly filled stomach it is clearly visible. many years been my experience that an exploratory laparotomy is not made when I have given a negative report, though a control by laparotomy would be a welcome event to me personally. Such a measure of trust, however, connotes no small personal responsibility, and I consider it my bounden duty to test the accuracy of my negative findings. For this purpose I use a rubber stamp which adds to the jeport the words, "If further clinical observation does not confirm the $x$-ray findings, please inform me."

In operation cases I only ask for information or (in hiospital) an invitation to attend when the operative findings do not appear to agree with the $x$-ray report. A further method of precaution is to call up again those

was completely free from carcinoma, but adherent in front. Death occurred within twenty-four hours with severe cardiovascular symptoms.

Cause of death: advanced arterio-sclerosis.

I now come to the erroneous positive diagnosis of early carcinoma. The more painstaking the endeavours to show that a slight variation from the normal is due to a small carcinoma, the greater the risk of a wrong diagnosis in tiae positive sense - that is, of diagnosing a carcinoma whe $n$ none is present.

As far as I know $T$ have not myself fallen into this particular kind of error in latter years. It is true that $I$ cond not in all cases find with any certainty whether the ca: e was ulcer or growth; ret I hold that it is possible in tle majority of cases to distinguish a carcinoma crater from an

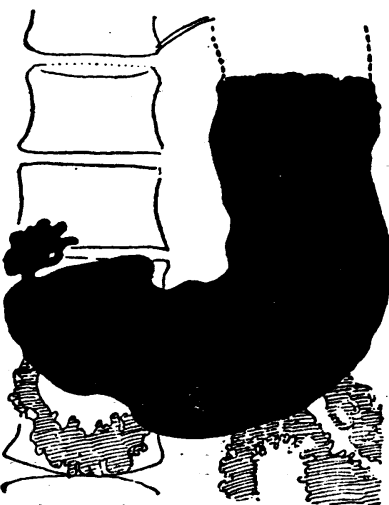

Fig. 11.-Same case as Fig. 10 stomach completely filledl; stomacl to all appearance normal. a few cases insoluble- of distinguishing between a benign and a malignant lesion in this region. The reason is this: the prepyloric segment is the most frequent site of carcinoma-about 80 per cent. of carcinomata start here. Uleers are certainly least commonly found here-occurring in about the proportion of 1 to 10 as compared with ulcers of the pars media. But the relatively small number of ulcers which occur in this region have three peculiarities which complicate the differential diagnosis:. (1) They show "niches" less frequently than in other situations. (Z) These ulcers are associated with more pronounced submucous oedema, with an increased tendency to spasm of the gastric musculature, and a greater degree of mucous membrane swelling. As a 
result the lumen of the pyloric part of the stomach is quite often narrowed, giving appearances similar to carcinoma. The following case (Case vi) is illustrative in this connexion.

\section{CASE VI.}

In a young man of 21 , who had suffered for four years from hyperacidity, the $x$-ray photograph showed in standing and prone positions a narrowing of the prepyloric segment with a defect with blirred outlines on both curvatures (Fig. 12). The appearances in themselves necessarily suggested carcinoma. The patient's healtlyy appearance, his youth, the duration of the symptoms, and increased acidity were against carcinoma. On clinical groun?ts a benign condition had therefore to be diagnosed, in spite of the $x$-ray appearances. And so I decided that it might well be a case of several ulcers close together. The operation confirmed this. A barium cast of the resected specimen corresponded exactly with the radiogram taken before the operation. A marked submucous oedema (rather uncommon) around two ulcers had caused the shadow defect. One surgical authority (Jedlicka) has emphasized the liability of prepyloric ulcers to submucous oedema.

A very exact analysis of the appearances often lielps one to a correct conclusion, but not always.

(3) The third peculiarity is the marked tendency of prepyloric ulcers to malignant degeneration.

My own experience agrees with the facts established by Orator $^{9}$ on material from the Eiselsberg Clinic, that about onc-third of prepyloric ulcers undergo cancerous degeneration, but only 3 per cent. of ulcers of the pars media, and hardly ever a duodenal ulcer. The difficult differential diagnosis and the tendency to malignant degeneration are sound reasons for recommending operation in preprloric ulcer.

The diagnosis of these ulcers is in a certain sense a contribution to the carly diagnosis of gastric carcinema. Warly recognition of malignant degeneration of ulcer is really the province of the histological investigation, and extremely unreliable by $x$-ray investigation.

Fven when there is no peptic ulcer. conditions simulating carcinoma may occur in the prepyloric segment caused by non-malignant thickening and contractions of the wall.

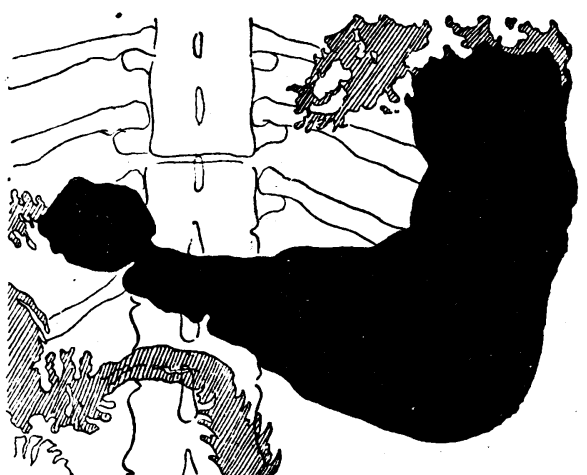

Fig. 13.-Flattening of lesser curvature simulating growth (prone position). been advised. I considered the narrowing to be due to a benign condition, as the longitudinal pyepyloric folds were present in the erect position (arrow, Fig. 14), and in the prone position the eccentricity of the small prepyloric barium mass is clearly seen to be towards the greater curvature side. The fine indentation is merely due to thickened mucosa. Peristalsis in the prone position is normal. I determined the cause of the abnormality to be the presence of a "common mesentery," in which condition the jejunum lies to the right of the stomach, and the caecum lies in the mid-abdominal region. On the strength of my findings no operation was performed.

I should liko to say something in conclusion on the significance of gastritis in the early diagnosis of gastric carcinoma.

The difference between the gastritis in patients with ulcer and gastritis in patients with carcinoma is the subject of increasing comment in surgical and pathological literature. According to Orator, the inflammatory changes in ulcer are confined to the prepyloric segment, in cancer they are generalized and show the picture of high-grade atrophy of the mucous nembrane.

In ulcers which had become carcinomatous, as proved by histological examination, Orator found, in the majority of cases, the pyloric gastritis characteristic of ulcer, in contradistinction to the cases of true carcinoma.

If the claim, put forward with due reservations, should be erentually established-namely, that it is possible anatomically to distinguish a precancerous gastritis from a gastritis associated with predisposition to ulcer-then Konjetzny would be justified in his suggestion that the resection of the precancerous gastritis represents the early operation on a carcinoma. In this case the study of the relief pattern of the mucous membrane in gastritis would offer an extremely promising line of research.

Wo may fairly hope, wo may reasonably expect, that it will fall to our lot to attain in the future yet greater success in the diagnosis of tho smallest tumours and of malignant changes in the mucosa over and above the results hitherto reached-results which, as I have shown, are cren now by no meaus to be despised. One thing is certainthat none but men equipjed with a sound knowledwe of pathology, clinical Regional gastrospasm, the cause of which is still unexplained, circumscribed fibromatosis-linitis plastica-and gastric syphilis must be mentioned in this comnexion. Atropine and papaverin usually fail to overcome the condition of spasm. Only by the fact that the course of the discase does not correspond with that of cancer, or by the presence of normal acidity, is the benign character of the disease occasionally recognized in these rare conditions.

In case of doubt one will never dare to put off recourse to operation. On these and other still slighter deformities of a harmless nature which alter the prepyloric segment by tapering it to a point and bending it, and may therefore add to the difficulties of early diagnosis of scirrhus, I have already reported at Stockholm. ${ }^{10}$ I give here an instance of one from the group of cases just mentioned.

\section{Case VIL}

In a doctor of 40 a narrowing of the prepyloric region, shown in Fig. 13 (prone) and in Fig. 14 (erect), had been interpreted by another observer as scirrhus, and resection of the stomach had medicine, and radiology can ever help cancer sufferces's to the earliest possible diagnosis and cure of their disease.

\section{REFERENCES,}

1 Clairmont und Haudek, Jena, Fischer, 1911.

2 Schönbauer und Fricdil: Wien. hlin. Woch., 1926, No. 32.

${ }^{3}$ Fränkel: Furtscluitte a. d. Gebicte d. Röntgenstrahlcn, Bd. 34, Ifeft 1 und 2.

4 Berg: Schleimhantrelinf des Magens bei verschiedenen Erkrankungen, Verhandlungen der (icsellxchaft für innere Medizin, 1926, S. 384.

5 Chasul: Deut. Zeit. für ' 'hir., Bd. 214, Heft 6.

-Wechselmann: Polyp und Carcinom am Magen-Darmkanal, Eruhns Beitriige, 1910, Bil. 70 .

?Anschütz und Konjctziu: Dic Gcschwülste des Magcns, Deut. C'lirırgie, 46, 1 IIälfte, 2 'Teii, 1921, Stuttgart.

8 Haudek: Zur Frage der Verlässlichkeit der Magennische für die Vleusdiagnose, Fortschritte a. d. Cebicte d. Röntgeustrahlen, Pd. 33, H. 5 .

9 Orator : Zur Pathologie und Genese des Carcinoms und Ulcuskarzinoms des Varens, Virchow's Archir, Bd. 255, H. 1.

10 Haudek. Zur Deutung der Veränderungen am präpvlorischen Maginabschnitt, Fortschritte a. d. Gicbicte d. Röntgenstrahlen, Bd. zo, 11. 4. 